\title{
FUNARI, Pedro Paulo Abreu. Paulo de Tarso, um apostolo para as nações. São Paulo: Paulus, 2013. ISBN: 9788534936293
}

\author{
Luciano Alves Silva1
}

Os autores Pedro Paulo Funari e Pedro Lima Vasconcelos são autoridades em temas histórico-bíblicos. Funari, que é paulistano, tem vasta experiência, com uma longa e ininterrupta carreira acadêmica, desde sua graduação (1981) em História pela Universidade de São Paulo, mestrado em Antropologia Social (USP, 1985), doutorado em Arqueologia (USP, 1990) e livre docência em história (UNICAMP, 1996). Ainda foi professor da UNESP (Assis, SP) e, desde 1992, atua como titular da cadeira de História Antiga na UNICAMP. É também pesquisador e professor atuante dentro e fora do país; com dezenas de livros e centenas de artigos escritos, muitos deles no exterior e tem se dedicado ao estudo das religiosidades antigas, bem como das identidades judaicas e cristãs.

Vasconcelos, por sua vez, nasceu na Barra do Piraí (RJ), é graduado em filosofia (UNIFAI, 1992) e teologia (faculdade de teologia Nossa Senhora da Assunção - SP, 1988), mestre em ciência da religião (UMESP, 1994), doutor em antropologia (PUC/SP, 2004) e livre docente em Ciências da religião (PUC/SP, 2009). Foi professor de teologia do Centro Universitário Salesiano de São Paulo e atualmente é professor de filosofia e ciências sociais da Universidade Federal de Alagoas e segue desenvolvendo pesquisa no campo das Religiões e suas produções simbólicas.

Os autores são muito felizes em relação à produção do livro, sobre a vida de uma personagem tão importante como Paulo de Tarso e esclarecem que se trata de uma abordagem breve. Ainda assim, entendemos que o texto será muito relevante para pesquisadores de todos os níveis, que estudam a vida e obra do autor mais profícuo do NT, e também beneficiará interessados em pesquisas sobre o Cristianismo primitivo.

Embora o exemplar resulte num pequeno livro de pouco mais de cem páginas, a bibliografia apresentada é bastante importante, contemplando

1 Mestre pela Universidade Federal de São Paulo, São Paulo, Brasil. E-mail: luciano.ibec@gmail.com 
nomes como os de Jeremy Murphy-O'connor, James Dunn, John Dominic Crossan, Jonathan L. Reed, Michel Quesnel, Chantal Reynier, dentro outros não menos importantes autores e autoras, e ainda disponibilizam breve cronologia, que contempla eventos pontuais, indo desde o início do Principado romano até a descoberta dos Manuscritos do Mar Morto, em 1947.

Um detalhe que não escapará ao leitor atento é o fato de que os autores argumentam que Paulo vivia numa cidade cosmopolita, aberta tanto para o Oriente como para o Ocidente, num cadinho de culturas; uma cidade de história antiquíssima, com mais de cinco mil anos a.C., que tornara-se colônia romana por Pompeu, no I Século a.C., e na qual a comunidade judaica estava presente desde a época de Alexandre, a partir dos Selêucidas, distribuídos por todo o império e mesmo em outras partes (p.29).

Os autores entendem que para a maioria das pessoas de idioma grego, tanto o nome Saul como Paulo eram estranhos. Porém, observamos que, uma vez que existem todos esses contextos, não se poderia estranhar a presença de nomes nem latinos nem hebraicos nessas regiões. Se relembrarmos os exemplos das invasões sofridas pelos judeus, levados cativos pelos assírios em 722 a.C. e pelos babilônicos em 586 a.C. teremos que, a presença de judeus em outras nações (nestes casos, forçosamente) era uma realidade. E mesmo no período chamado interbíblico, entre a escrita de Malaquias e do Novo Testamento, muitas comunidades judaicas estavam estabelecidas em toda região do atual Oriente Médio e do Mediterrâneo, isto, mesmo antes da época de Alexandre e dos posteriores, Selêucidas.

Já no Novo Testamento, o autor do livro de Atos, quando escreve a respeito do Pentecostes, argumenta que havia em Jerusalém, por ocasião dessa festividade, judeus oriundos de muitas nacionalidades diferentes: Partos, medos e elamitas; habitantes da Mesopotâmia, Judéia e Capadócia, Ponto e da província da Ásia, Frígia e Panfília, Egito e das partes da Líbia próximas a Cirene; visitantes vindos de Roma, tanto judeus como convertidos ao judaísmo; cretenses e árabes (Atos 2:9-11). Por sua vez, o apóstolo Pedro escreverá às comunidades judaico-cristãs espalhadas no Ponto, no Galácia, em Bitínia, na Capadócia e Ásia Menor (I Pe. 1.2). E também Tiago escreverá sua carta às Doze Tribos dispersas entre às nações ( $\operatorname{Tg} 1.1)$. Assim, entendemos que a presença de judeus era 
uma realidade em todo o mundo de então, o que incluía, naturalmente, a região de Tarso de Cilícia², cidade originária de Paulo.

Então, presumimos que nomes judaicos e latinos eram, em alguma medida, comuns naquelas regiões. Os judaicos por conta da natureza desse povo, que desde sempre fora espalhado e quase nômade; os latinos pela presença romana, não apenas pelo fato de a região estar sob o domínio romano, mas também pelo fato de Tarso ser uma cidade cosmopolita onde as culturas mais variadas eram apreciadas pelos seus habitantes, habituados a leitura de poetas e filósofos, latinos e gregos. $\mathrm{O}$ geógrafo Estrabão, nos primeiros anos do primeiro século da era cristã escreve que o povo de Tarso era ávido por atividades culturais; que se dedicavam ao estudo da filosofia, das artes, e de todo círculo de aprendizado em geral ${ }^{3}$.

Os autores argumentam ainda que era difícil imaginar Saul (como o chamam no livro), perseguidor do insipiente movimento cristão e seguidor de Gamaliel, ao mesmo tempo (p.30). Entendemos que essa atitude paulina traduzia muito do seu comportamento. Ele, que era relativamente jovem para época, mostrava-se impulsionado por um lado pelo radicalismo religioso e, por outro lado, ao academicismo e piedade farisaicos de Gamaliel.

Por algumas razões vemos que a motivação que impulsionava o jovem Saul ao radicalismo diverge dos argumentos dos autores. Talvez, o fato de ser jovem (Atos 7.58), nos faz lembrar que são os jovens os que, motivados por ideologias mais radicais, protagonizam, geralmente, as ações mais exageradas.

Outro elemento está ligado àquilo que mais tarde o próprio Saul escreverá "que o saber ensoberbece, mas que o amor edifica". (I Co 8.1) Noutras palavras, sua juventude ligada ao conhecimento que tinha pode tê-lo tornado orgulhoso (como é próprio do academicismo) e também cheio de interesses pessoais, de modo que estar em Jerusalém e aos pés de Gamaliel era o sonho de qualquer jovem que tivesse vocação religiosa, como era o caso de Saul. E, quem sabe, se ele não tinha interesse em tornar-se o sucessor do próprio Gamaliel?

Os autores também tentam explicar a razão pela qual os apóstolos de Jerusalém se dispuseram a visitar comunidades fundadas por Paulo.

\footnotetext{
2 JEREMIAS, Joachim. Jerusalém nos tempos de Jesus. Tradução de M. Cecília de M. Duprat. São Paulo: Ed. Paulinas, 1983. 95 p.

3 STRABO. ed. H. L. JONES. The Geography of Strabo. Cambridge, Mass.: Harvard University Press; London: William Heinemann, Ltd. 1924.
} 
Segundo seus argumentos, essas visitas tinham a finalidade de circuncidar os novos convertidos ao Cristianismo. De fato, há na Galácia aqueles que se deixaram circuncidar, mas não fica claro pelas passagens bíblicas que foram os apóstolos de Jerusalém que o fizeram. O que Paulo deixa claro no seu texto é que, aqueles que se deixavam circuncidar deveriam observar toda a Lei de Moisés (Gl 5.3).

Marcião, do século II, é citado pelos autores como aquele que tentou distorcer o Cristianismo argumentando que o Deus do AT não era o Pai de Jesus Cristo, com isso rejeitava todo o Antigo Testamento e acrescentava ao NT textos tidos como apostólicos, mas essencialmente inconsistentes e contraditórios (p.89). Segundo os autores, a partir de Marcião é que textos, tidos como paulinos foram acrescentados, para rechaçar os ensinos marcionistas. De modo que, o que se tem no Novo Testamento como cartas escritas por Paulo, nem todas podem assim ser consideradas.

Mas, seria importante, pelo que entendemos, que fosse contemplada outra parte da discussão neste particular sobre os autógrafos, uma vez que há argumentos de teólogos e historiadores que admitem a autenticidade paulina de treze cartas presentes no NT. Estes baseiam-se no fato de que desde o século I até o início do século XIX a autoria paulina era universalmente aceita, e foi somente a partir do começo do século XVIII que estudiosos alemães como Baur, Barth ${ }^{4}$, Houlden ${ }^{5}$ e outros, começaram a questionar a autenticidade de algumas de suas cartas.

Para citar apenas uma delas, na carta aos Efésios - alguns destes historiadores advogam que o vocábulário, o estilo e os conteúdos próprios de Paulo ali não ocorrem, nem as palavras prediletas do apóstolo podem ser encontradas nesta carta ${ }^{6}$. Já, para os que defendem a autenticidade paulina da carta, os argumentos dos alemães são bastante subjetivos, uma vez que Paulo tem uma mente muito criativa, sendo capaz de transitar por variados estilos com riqueza de vocabulário; e que, temas diferentes requerem palavras diferentes e circunstâncias alteradas requerem vocabulário próprio 7 .

\footnotetext{
${ }^{4}$ BARTH, Markus. The broken wall: a study of epistle of Ephesians. United Kingdom: Collins, 1960. $12 \mathrm{p}$.

${ }^{5}$ HOULDEN, J. H. The Pelican New Testament Commentaries. Paul's Letters from prison: Philippians, Colossians, Philemon and Ephesians. London: 1970. 235 p.

${ }^{6}$ HOULDEN, J. H. The Pelican New Testament Commentaries. Paul's Letters from prison: Philippians, Colossians, Philemon and Ephesians. London: 1970.106 p.

7 STOTT, John. R. W. A mensagem de Efésios. São Paulo: ABU Editora; $5^{\text {a }}$ edição. 2 p.
} 
Assim, os estudiosos que defendem que as cartas presentes no NT são autenticamente paulinas se valem inclusive do próprio estilo usado na escrita do documento, na erudição presente nas cartas e em aspectos teológicos recorrentes em todas elas ${ }^{8}$. O teólogo anglicano, o britânico John Stott, em seus argumentos afirma que:

(...) a antiga visão de que essas cartas são autenticamente paulinas recusam-se a desvanecer. Durante o século XX uma vigorosa defesa foi montada por eruditos, tanto evangélicos quanto católicos, dentre eles destacam-se Newport J.D. White (1910), Walter Lock (1924), Joachim Jeremias (1934), C. Spicq (1947), E. K. Simpson (1954), Donald Guthrie (1957), William Hendricksen (1957), J. N. D. Kelly (1963), Gordon D. Fee (1984), Thomas C. Oden (1989), George W. Knight (1992) e Philip H. Towner (1994). Enquanto que os argumentos contrários à autenticidade paulina passam por questões históricas, linguísticas, teológicos e éticos 9 .

Devemos lembrar que os autores citados acima, embora confessionais, tratam-se de pesquisadores teólogos, filósofos e historiadores que buscam compreender melhor as Escrituras e, assim, trazem à luz suas pesquisas para possibilitar discussões como estas. Além disto, independentemente do ponto de vista, todos os documentos presentes no NT têm autenticidade e autoridade históricas.

Enfim, o livro é altamente recomendável, pois ao pesquisar com tanto primor a história deste personagem fundamental do NT, os autores nos ajudam a compreender detalhes importantes da origem da sua vida, da sua determinação, especialmente depois da sua conversão ao Cristianismo. E esforços como esses vêm cooperando para que tenhamos esse arcabouço tão fundamental de saberes histórico-bíblicos, o que nos ajuda a reconstituir parte daquilo que nos é tão caro e que, ao mesmo tempo, está tão distante de nós. Assim, somos gratos a exemplares como este livro que nos chegam às mãos, que ampliam a discussão e enriquecem o debate, que tarda a esvanecer.

\footnotetext{
8 STOTT, Ibidem.

9 STOTT, John. R. W. A mensagem de I Timóteo e Tito. Tradução de Milton Azevedo de Andrade. São Paulo: ABU Editora, 2004. 16 p.
} 